\title{
Massage Therapy
}

National Cancer Institute

\section{Source}

National Cancer Institute. Massage Therapy. NCI Thesaurus. Code C15276.

A therapeutic method of manipulation, methodical pressure, friction, and kneading of the body. (from Taber's) 